Hope College

Hope College Digital Commons

Faculty Publications

$11-9-2017$

\title{
It's More Than Self-Presentation: MUM Effects Can Reflect Private Discomfort and Concern for the Recipient
}

Jayson L. Dibble

Hope College, dibble@hope.edu

Follow this and additional works at: https://digitalcommons.hope.edu/faculty_publications

Part of the Cognition and Perception Commons, Cognitive Psychology Commons, Interpersonal and Small Group Communication Commons, Quantitative Psychology Commons, and the Social Psychology Commons

\section{Recommended Citation}

Repository citation: Dibble, Jayson L., "It's More Than Self-Presentation: MUM Effects Can Reflect Private Discomfort and Concern for the Recipient" (2017). Faculty Publications. Paper 1452.

https://digitalcommons.hope.edu/faculty_publications/1452

Published in: Communication Research Reports, Volume 35, Issue 2, November 9, 2017, pages 112-120. Copyright @ 2017 Taylor \& Francis.

This Article is brought to you for free and open access by Hope College Digital Commons. It has been accepted for inclusion in Faculty Publications by an authorized administrator of Hope College Digital Commons. For more information, please contact digitalcommons@hope.edu. 
It's More Than Self-Presentation: MUM Effects Can Reflect Private Discomfort and Concern for the Recipient

Jayson L. Dibble Hope College

Author Note

Jayson L. Dibble (Ph.D., 2008, Michigan State University) is an associate professor in the Department of Communication at Hope College.

Correspondence concerning this article should be addressed to Jayson Dibble, Department of Communication, Hope College, 257 Columbia Ave., Holland, MI 49423. E-mail: dibble@hope.edu 


\begin{abstract}
Is the reluctance to share bad news (i.e., the MUM effect) motivated more by a public display or private concern, and does it benefit mainly the messenger or the recipient? An experiment $(N=$ 309) that crossed good/bad news with three communication channels (face to face, text messaging, email) revealed that messenger reluctance was greatest under conditions of bad news and did not vary based on channel through which the recipient contacted the messenger. In contrast with earlier work, this MUM effect was more consistent with a private fear of distressing the recipient. Theoretical implications and limitations are discussed.
\end{abstract}

Keywords: bad news, MUM effect, negative feedback, interpersonal communication 
It's More Than Self-Presentation: MUM Effects Can Reflect Private Discomfort and Concern for the Recipient

The MUM effect (keeping Mum about Undesirable Messages, Rosen \& Tesser, 1970) describes the reluctance and/or hesitation messengers experience when faced with having to share bad news with a recipient for whom the news is bad, and MUM effects can hinder effective delivery of bad news. Research organizes the causes of MUM effects along two central questions. First, are MUM displays driven mainly by the messenger's public need to be viewed positively by the recipient, or by a private discomfort associated with hurting the recipient (e.g., Bond \& Anderson, 1987)? Second, do MUM effects reflect a messenger's concerns about the self or the other (e.g., Dibble \& Levine, 2013; Jeffries \& Hornsey, 2012; Kardes \& Kimble, 1984)?

Unfortunately, many of these same studies inadvertently confuse these two questions. Perhaps the common reliance on self-presentation theories to explain MUM effects invites some of this confusion as the expression self-presentation itself conflates the two dimensions; i.e., the self aspect of "self/other" gets conflated with the public presentation aspect of "public/private." Sharp theorizing about the MUM effect requires keeping these distinctions intact.

According to various self-presentation theories (e.g., Brown \& Levinson, 1987; Goffman, 1967; Wilson, Aleman, \& Leatham, 1998) face involves how the messenger and the recipient want to be viewed by each other. Importantly, if one supports or attacks the other's face, one does likewise to their own face. Invoking self-presentation theories without special care invites murky interpretation because public/private comparisons do not address whether the messenger is focused more on their own face or on the recipient's. Any public MUM effect might serve the messenger, the recipient, or both. Studies that have claimed self-oriented MUM effects (e.g., 
Bond \& Anderson, 1987; Dibble \& Levine, 2013; Jeffries \& Hornsey, 2012; Kardes \& Kimble, 1984; Uysal \& Oner-Ozkan, 2007) may lack the nuance called for by face approaches.

Moreover, multiple face concerns may operate simultaneously while breaking bad news, some of which serve the messenger and some that serve the recipient (Wilson et al., 1998). The current study accounts for this possibility by employing measurement items that tap both self- and otherfocused face concerns.

\section{MUM Effects and Communication Channel}

Communication channels vary in their affordances to messengers. For example, email compared to face-to-face is less immediate, asynchronous, and may provide a buffer between the messenger and the recipient. As a result, messengers who delivered bad news via email communicated the message more thoroughly and with less distortion, presumably because they felt less threatened (Sussman \& Sproull, 1999). I extend this research on channels by utilizing a scenario where the recipient, not the messenger, not only initiates (what could potentially become) the bad news disclosure, but also chooses the channel through which to contact the would-be messenger. Would the channel dynamics observed by Sussman and Sproull replicate in this unique context? That is, does the channel weigh on the messenger's mind if the recipient reaches out first?

\section{Research Propositions}

Good news by definition does not trigger MUM effects; therefore, the communication channel used may be moot for messengers who deliver good news (Sussman \& Sproull, 1999). Bad news threatens the faces of the recipient and the messenger. In addition, these face threats should be more pronounced when the recipient approaches the messenger in person compared to using less immediate channels (e.g., text message, email). A MUM effect driven by public 
display should manifest in an interaction between news valence and communication channel such that recipients who approach the messenger face-to-face will prompt more reluctance than recipients who contact the messenger via email, whereas under conditions of good news reluctance will not be impacted by channel $(\mathrm{H} 1)$. In the case of bad news, to see no difference in reluctance according to channel would be more consistent with the MUM reluctance being a matter of private discomfort.

A key contribution of this study is that it also addresses in the same design the selforiented versus other-oriented dimension. If reluctance is driven mainly by the messenger's selfenhancement, then the levels of messenger-oriented concern (e.g., "don't shoot the messenger") should exceed those of recipient-oriented concern (H2a). If reluctance is recipient-oriented (e.g., driven by the thought of harming the recipient), then levels of recipient-oriented concern should exceed those of messenger-oriented concern $(\mathrm{H} 2 \mathrm{~b})$. To see no differences among the various messenger concerns might reflect concerns for both the messenger and the recipient $(\mathrm{H} 2 \mathrm{c})$.

\section{Method}

I tested the hypotheses using a 2 X 3 between-subjects experiment wherein two levels of news valence (good/bad) were fully crossed with three communication channels (face to face, text messaging, email). The research was IRB approved.

\section{Participants}

Participants $(N=360 ; 67.9 \%$ female) were undergraduates from various communication courses at a small, liberal arts college in the Midwest $\left(M_{\text {age }}=19.77\right.$ years, $\left.S D=2.66\right)$. Participants were mostly Caucasian/White (81.6\%), followed by African American/Black (5.3\%), Asian/Pacific Islander (4.5\%), Hispanic (4.5\%), Multi-racial (2.2\%), and Other (1.9\%); and each received course credit for participating. 


\section{Procedure}

All experimental stimuli and measures were distributed via the Internet-based platform SurveyMonkey®. After obtaining informed consent, participants were randomly assigned to read one of six versions of the same basic scenario. Participants were told to read and imagine themselves in the following situation:

You are a student at the College where you and a very close friend are in the same class. Your class just took a final exam on which you happen to know that your friend needed to score 75 percent in order to graduate on time. As it happens, your friend already had prearranged travel plans with family and was absent from class when the scores were released. By sheer accident, as the professor walked by your seat while handing back exam papers, you glimpsed your friend's exam score. Nobody but you knows that you have seen your friend's score.

Participants then read a follow-up message tailored to their experimental condition. In the follow-up, the friend returns from their travels and contacts the participant through one of three channels (in person/face to face, text message, email) asking if the participant happens to know how the friend performed. Following Sussman and Sproull (1999), I chose three channels to offer a range of affordance profiles (immediacy, synchronous/asynchronous, cue rich/lean, etc.) while still being plausible for college students. The scenario indicated that the friend either achieved the score necessary to pass the class (good news, $n=174,48.3 \%$ ) or failed to do so (bad news, $n=186,51.7 \%$ ). Hypothetical exam scenarios in MUM effect research have been effective with college student samples (e.g., Dibble, 2014; Uysal \& Oner-Ozkan, 2007; Weenig, Wilke, \& ter Mors, 2014). After reading their scenario, participants completed a self-report questionnaire, then read a statement of debriefing and thanks.

\section{Measures}

We measured the following variables using dedicated sets of items to which participants responded using a 7 -step Likert response format $(1=$ strongly disagree, $7=$ strongly agree $)$. 
Higher numbers reflected greater amounts of the variable. Table 1 lists means, standard deviations, and zero-order correlations.

Perceived news valence. I measured participants' perceptions of the valence using six items created for this study, e.g., "My friend will graduate on time." Cronbach's $\alpha$ was .98, $n=$ 345.

Reluctance. Messenger reluctance was measured using five items adapted from Dibble and Sharkey (2017), e.g., "I wouldn't want to share my friend's score with them" $(\alpha=.91, n=$ 353).

Likelihood to share the news. Because the friends in the scenario were unaware that the participant actually knew the score, participants were free to withhold the news entirely. I measured the participant's likelihood of sharing the friend's score using four items, e.g., "I would tell my friend how they did on the exam" $(\alpha=.94, n=355)$.

Fear of being evaluated negatively. Being seen in a negative light by the recipient (e.g., Buckman, 1984) is self-focused. The more that MUM effects are motivated by messengeroriented concerns, the greater this fear should be. I assessed this fear using five items taken from Dibble (2014) and modified to the current study, e.g., "I would worry my friend would think of me as being insensitive" $(\alpha=.93, n=350)$.

Fear of being blamed. Messengers sometimes hesitate because they fear the recipient will blame them for the bad news (Buckman, 1984), another self-focused concern. This was assessed using six items again from Dibble (2014), e.g., "Don't shoot the messenger would be running through my head" $(\alpha=.91, n=346)$. 
Fear of distressing the recipient. Fear of distressing the recipient is a common recipient-focused concern (Buckman, 1984). I measured this concern using six items from Dibble (2014), e.g., "I would be afraid of hurting my friend's feelings" $(\alpha=.96, n=342)$.

Control variable: Obligation. Messengers who feel a sense of duty may share the bad news irrespective of their own discomfort, perhaps because the recipient is a friend, and this might negate any MUM effect. To control for obligation to transmit the news, I used five items, e.g., "I would feel obligated to share my friend's score with them" $(\alpha=.88, n=349)$.

\section{Results}

\section{Induction Checks}

News valence. An independent samples $t$-test (that did not assume equal variances) revealed that the passing score was perceived much more positively $(M=6.51, S D=.70)$ than was the failing score $(M=1.71, S D=.99), t(320.70)=52.23, p<.001, r=.94$.

Communication channel. I measured whether participants could recall the channel through which the friend reached out to them. Although most participants $(n=309,85.8 \%)$ correctly indicated the condition to which they had been assigned, in the tests that follow I excluded as a precaution $n=51(14.2 \%)$ who failed to indicate their assigned channel. This yielded the following frequencies per channel: text message $n=131,42.4 \%$; in person/face to face $n=120,38.8 \%$; email $n=58,18.8 \%$.

\section{Homogeneity of Variance Checks}

Levene's test was not significant for likelihood to share the news, $F(5,293)=0.96, p=$ .45 , but was for reluctance, $F(5,293)=2.49, p=.03$. However, even small differences in variance can produce a significant Levene's result because of the improved power of the test (Field, 2009). Follow-up testing using Hartley's Fmax table yielded a ratio of 1.68 between the 
largest group variance (2.08 for good news/text message) and the smallest variance (1.24 for good news/in person). This ratio is below the critical value $[\mathrm{CV}=2.91, d f=30$ (the smallest cell $n=26$ ), K groups $=6$ ], suggesting these data do not violate the assumption of homogeneity of variance.

\section{Tests of Hypotheses}

I predicted an interaction between news valence and communication channel such that the channel would affect messenger reluctance when the news was bad but not when the news was good (H1), and tested this hypothesis using two-way ANCOVA with reluctance as the dependent variable and obligation as a covariate. Obligation was significantly related to reluctance, $F(1,292)=33.25, p<.001, \eta^{2}=.04$. Consistent with the MUM effect, a significant main effect emerged for news valence condition, $F(1,292)=474.43, p<.001, \eta^{2}=.53$, such that bad news triggered more reluctance $(M=5.44, S D=1.16)$ than did good news $(M=2.27$, $S D=1.25)$. However, there was no main effect for communication channel condition, $F(2,292)$ $=0.51, p=.60, \eta^{2}<.001$, nor any significant interaction, $F(2,292)=0.13, p=.88, \eta^{2}<.001$. Whether the news was good or bad, messenger reluctance did not vary whether the friend reached out in person $(M=3.87, S D=1.95)$, via text $(M=3.96, S D=2.08)$, or via email $(M=$ 3.55, $S D=1.83$ ). A follow up test using likelihood to share the news as the dependent variable produced similar results: Significant effect for news valence condition, $F(1,292)=64.40, p<$ $.001, \eta^{2}=.11$ (i.e., the MUM effect replicated), but no effect for communication channel, $F(2$, $292)=0.32, p=.72, \eta^{2}<.01$, and no interaction, $F(2,292)=1.26, p=.29, \eta^{2}<.01$. Data are neither consistent with $\mathrm{H} 1$ nor with the public display explanation when the MUM effect occurs in situations where the recipient initiates the conversation. 
For H2, I used multiple linear regression to regress reluctance onto the three face concern variables: fear of being blamed, fear of being evaluated negatively, and fear of distressing the recipient; and compared the standardized coefficients to estimate which concern(s) are most associated with reluctance. The predictors were correlated with each other $(r s=.45-.75)$ but multicollinearity diagnostics did not indicate a problem (tolerances $=.34-.67, \mathrm{VIF}=1.49-2.92)$. The overall model was significant, $F(3,272)=122.56, p<.001$, adjusted $R^{2}=.57$. Fear of distressing the recipient $(\beta=.79, t=12.59, p<.001)$ and fear of being blamed $(\beta=.12, t=2.39$, $p=.02)$ both predicted reluctance, but fear of being evaluated negatively did not $(\beta=-.12, t=-$ $1.73, p=.09$ ). Using likelihood to share the news as the dependent variable corroborated the results: Fear of distressing the recipient $(\beta=-.29, t=-3.30, p=.001)$ and fear of being blamed $(\beta=-.15, t=-2.18, p=.03)$ were both negative predictors, but once again fear of being evaluated negatively was not $(\beta=-.06, t=-0.58, p=.56)$. Although small effects emerged for fear of being blamed, the pattern of regression coefficients suggests that reluctance and likelihood to share the news were driven more by the recipient-oriented concerns $(\mathrm{H} 2 \mathrm{~b})$ than by the messenger-oriented concerns (H2a).

\section{Discussion}

Prior studies have cast MUM effects as largely driven by a public need for messengers to self-enhance. The MUM effect produced here- using hypothetical scenarios and felt reluctance as the outcome - was more consistent with private discomfort than a public display. Moreover, when assessing specifically messengers' concerns, the other-oriented concern (fear of distressing the recipient) drove reluctance, and the self-oriented concerns did not associate as strongly with reluctance nor with likelihood to transmit the news. 
One primary difference between the prior studies and the current experiment involves the nature of the outcome measures used. Earlier experiments generated behavioral MUM effects (e.g., Bond \& Anderson, 1987; Dibble \& Levine, 2013; Jeffries \& Hornsey, 2012). The current study utilized psychological MUM variables (reluctance, likelihood to transmit). Interestingly, although participants noticed the channel through which their friend made contact, the reluctance they reported was unmitigated by this channel. Perhaps internal reluctance owes more directly to the negative nature of the bad news, and the channel's relevance pertains more to the messenger's actual communication with the recipient. This prompts interesting questions about the causal positioning among factors like perceived news valence, reluctance, face threats, channel choices, etc., and future research should investigate these.

In addition, the experimental scenario had a close friend initiate the conversation with the messenger. Perhaps interpersonal closeness between the messenger and the recipient mitigated the public need to self-enhance since the recipient already knows the messenger well. Indeed, close friends can be bolder and more forthcoming about the negative aspect of the news either because of a heightened motive to protect their friend (Dubois, Bonezzi, \& De Angelis, 2016), or even to build affiliation through playful teasing (Dibble \& Levine, 2013). In any event, in contrast to many of the behavioral studies, the MUM situation instantiated here seems to have been private and other-oriented.

\section{Limitations and Conclusion}

First, this study utilized an imagined scenario. Although this is well established in prior MUM effect research and supported in other social research (e.g., Hughes \& Huby, 2004), the question is open whether messengers' behavior would correspond to hypothetical reporting. However, participants clearly viewed the passing exam as good news and the failing exam as bad 
news, and the pattern of face threats driving reluctance was consistent with a friend (fear of distressing the recipient was operant) who had passed/failed an exam of their own doing (fears of being blamed and being evaluated negatively were less relevant because the messenger knows the recipient was responsible for their own fate). If participants were not attending to the scenarios as designed, these data become difficult to explain. Second, this sample relied on college students, which limits generalizability. However, my purpose was to test specific effects in a unique context, and we did so using a scenario that is very plausible and relatable to a college student. Finally, although MUM effects obtained in our scenario where the recipient explicitly initiated an opportunity for the messenger to disclose the exam score, and participants correctly identified the channel through which they were contacted, the extent to which the channel loomed in the participant's thinking is uncertain. Perhaps channels only matter when the messenger has choice of channel (e.g., Sussman \& Sproull, 1999). Future designs can probe this issue more carefully.

MUM effect studies would do well to clarify not only public/private or self/other, but also whether the MUM outcomes in question are behavioral or cognitive/affective as these aspects may work in concert. For example, although it may be true that messengers communicate without distortion whatever they eventually say through channels like email (Sussman \& Sproull, 1999), internal stresses and reluctance may still drive them to hold back certain information. These data revealed that no matter how the recipient reached out to the participant, reluctance was unmitigated. Focusing on internal factors that influence how messengers encode their messages supplements understanding of the external behaviors that accompany MUM situations. Also future meta-analysis would be useful to compare across studies treating the behavioral — cognitive nature of the MUM outcome as a moderating factor. 


\section{References}

Bond, C. F., Jr., \& Anderson, E. L. (1987). The reluctance to transmit bad news: Private discomfort or public display? Journal of Experimental Social Psychology, 23, 176-187. doi:10.1016/0022-1031(87)90030-8

Brown, P., \& Levinson, S. C. (1987). Politeness: Some universals in language usage. Cambridge, UK: Cambridge University Press.

Buckman, R. (1984). Breaking bad news: Why is it still so difficult? British Medical Journal, 288, 1597-1599.

Dibble, J. L., (2014). Breaking good and bad news: Face-implicating concerns as mediating the relationships between news valence and hesitation to share the news. Communication Studies, 65, 223-243. doi:10.1080/10510974.2013.811431

Dibble, J. L., \& Levine, T. R. (2013). Sharing good and bad news with friends and strangers: Reasons for and communication behaviors associated with the MUM effect. Communication Studies, 64, 431-452. doi:10.1080/10510974.2013.770407

Dibble, J. L., \& Sharkey, W. F. (2017). Before breaking bad news: Relationships among topic, reasons for sharing, messenger concerns, and the reluctance to share the news. Communication Quarterly, 65, 436-455. doi:10.1080/01463373.2017.1286363

Dubois, D., Bonezzi, A., \& De Angelis, M. (2016). Sharing with friends versus strangers: How interpersonal closeness influences word-of-mouth valence. Journal of Marketing Research, 53, 712-727. doi:https://doi.org/10.1509/jmr.13.0312

Field, A. (2009). Discovering statistics using SPSS ( $3^{\text {rd }}$ Ed.). Thousand Oaks, CA: Sage. Goffman, E. (1967). Interaction ritual: Essays in face-to-face behavior. New York, NY: Pantheon. 
Hughes, R., \& Huby, M. (2004). The construction and interpretation of vignettes in social research. Social Work \& Social Sciences Review, 11, 36-51. doi:http://dx.doi.org/10.1921/swssr.v11i1.428

Jeffries, C. H., \& Hornsey, M. J. (2012). Withholding negative feedback: Is it about protecting the self or protecting others? British Journal of Social Psychology, 51, 772-780. doi:10.1111/j.2044-8309.2012.02098.x

Kardes, F. R., \& Kimble, C. E. (1984). Strategic self-presentation as a function of message valence and the prospect of future interaction. Representative Research in Social Psychology, 14, 2-11.

Rosen, S., \& Tesser, A. (1970). On reluctance to communicate undesirable information: The MUM effect. Sociometry, 33, 253-263.

Sussman, S. W., \& Sproull, L. (1999). Straight talk: Delivering bad news through electronic communication. Information Systems Research, 10, 150-166.

Uysal, A., \& Oner-Ozkan, B. (2007). A self-presentational approach to transmission of good and bad news. Social Behavior and Personality, 35, 63-78. doi:10.2224/sbp.2007.35.1.63

Weenig, M. W. H., Wilke, H. A. M., \& ter Mors, E. (2014). Personal outcomes and moral responsibility as motives for news transmission: The impact of fate similarity, fate uncertainty, and relationship closeness. Communication Research, 41, 404-429. doi:10.1177/0093650211402195

Wilson, S. R., Aleman, C. G., \& Leatham, G. B. (1998). Identity implications of influence goals: A revised analysis of face-threatening acts and application to seeking compliance with same-sex friends. Human Communication Research, 25, 64-96. doi:10.1111/j.14682958.1998.tb00437.x 
Table 1

Means, Standard Deviations, and Zero-Order Correlations for All Study Variables

\begin{tabular}{llllllll}
\hline Measure & 1 & 2 & 3 & 4 & 5 & 6 & 7 \\
\hline 1. News Valence & & & & & & & \\
2. Reluctance & -- & & & & & & \\
3. Likelihood to Share the News & $-.81^{*}$ & -- & & & & & \\
4. Fear of Being Evaluated Negatively & $.37^{*}$ & $-.62^{*}$ & -- & & & & \\
5. Fear of Being Blamed & $-.44^{*}$ & $.51^{*}$ & $-.37^{*}$ & -- & & & \\
6. Fear of Distressing the Recipient & $-.34^{*}$ & $.39^{*}$ & $-.30^{*}$ & $.59^{*}$ & -- & & \\
7. Obligation & $-.73^{*}$ & $.74^{*}$ & $-.39^{*}$ & $.76^{*}$ & $.47^{*}$ & -- & \\
& .11 & -.29 & $.62^{*}$ & -.08 & -.08 & -.07 & -- \\
Mean & & & & & & & \\
$S D$ & 4.02 & 3.89 & 5.17 & 3.26 & 2.12 & 4.07 & 4.56 \\
$N$ & 2.55 & 1.95 & 1.64 & 1.72 & 1.29 & 2.01 & 1.39 \\
\hline & 345 & 353 & 355 & 350 & 346 & 342 & 349 \\
\hline
\end{tabular}

Note. $* p<.01$ 